\title{
Elevated Sedimentation Rate
}

National Cancer Institute

\section{Source}

National Cancer Institute. Elevated Sedimentation Rate. NCI Thesaurus. Code C162111.

A higher than average sedimentation rate in a sample. 